\title{
The DOW 30's Compliance with the Provisions of SFAS 159 and 157 for Investments in Equity Securities
}

Veliota Drakopoulou*

Forbes School of Business, The Forbes School of Business at Ashford University, USA

\begin{abstract}
Although, SFAS 159 has raised the bar for disclosure requirements and improved investors, analysts, and financial statement users understanding of managements' rationale for implementing the Fair Value Option (FVO) for equity securities, it has been criticized to prospect entities to structure transactions that are intended to lever a specific accounting effect. Companies by appointing the fair value option for underwater investments in certain securities can move those securities from the available-for-sale and held-to-maturity categories into the trading category and record the unrealized losses as an essential portion of the cumulative-effect adjustment to retained earnings without reproducing any losses on the securities in the income statement even if the securities subsequently are sold. This study examines how the thirty companies that comprise the Dow Jones Industrial Average (Dow 30) complied with the provisions of SFAS No. 157 and 159 to record their investments in equity securities. The results indicate that the sample of companies complied with the qualitative guidelines outlined in the pronouncement. A surprising finding was that a large number of the sample companies reported that they don't currently believe adoption would have a material impact on their consolidated results of operations and financial condition.
\end{abstract}

Keywords: Fair value; FVO; Investments in debt and equity securities; Financial assets; Financial liabilities

\section{Introduction}

Accounting for investments in equity securities has originated a great deal of interest over the past several years. The primary area of concern is the disclosure of changes in the market or fair value of equity securities. The value of investment securities can change dramatically in a short period of time causing the accounting information signaling this change in value to be advantageous to businesses and financial statements users. The Financial Accounting Standards Board (FASB) raised the disclosure requirements of Statement No. 159 [1], “The Fair Value Option for Financial Assets and Financial Liabilities, including an amendment of FASB Statement No. 115," issued on February 15, 2007 in an effort to lead investors, analysts and other financial statement users to identify how changes in fair values of equity securities are reflected in the financial statements. The fair value option (FVO) increased entities capacity to decide on measurement attributes for certain assets and liabilities by allowing business entities to measure financial instruments at fair value on an "instrument-by-instrument" denoting a financial reporting evolution. SFAS No. 159 has been criticized by Mr. Linsmeir [2], one of the five Board Members of FASB to significantly decrease the accuracy of financial reporting by failing to represent the earnings effects of equity securities disclosures in the same reporting period due to the partial adoption of fair values resulting from the instrument-by-instrument option. Mr. Linsmeir [2] argued that an instrument-by-instrument option that results in partial adoption of fair values for only some financial instruments significantly reduces the relevance of the resulting reporting by failing to portray the earnings effects of financial instruments' exposures in the same reporting period and increases users' costs in processing the information by introducing treatment alternatives that reduce the comparability of reported results within and across reporting entities and line items. For these reasons, Mr. Linsmeier [2] does not agree that this Statement represents a costbeneficial interim step toward measuring all financial instruments at fair value a long-term goal stated by the Board in Statement 133. Rather, he believes users of financial statements would be better served by accelerating efforts to issue a Statement requiring all financial instruments to be measured at fair value each reporting period with changes in those fair values reported in earnings [1].

\section{FASB Statements No. 159 and No. 157}

The FASB raised the disclosure requirements of Statement No. 159 by requiring companies to provide additional information that is intended to help investors and other users of financial statements to more easily understand the effects of reported earnings of the company's choice to use fair value by mitigating reporting volatility in earnings that results from using different measurement attributes in reporting related financial assets and financial liabilities. SFAS No. 159 affirms that all available-for-sale (AFS) and held-to-maturity (HTM) securities held at the effective date are eligible for the fair value option at that date. If the fair value is elected for any of those securities at the effective date, cumulative unrealized gains and losses at that date shall be included in the retained earnings cumulative-effect adjustment. The amount of unrealized gains and losses reclassified from accumulated other comprehensive income for AFS and HTM securities should be separately disclosed [1]. If the entity designates the fair value option for a HTM or AFS security in conjunction with adopting SFAS 159, that security shall be reported as a trading security under SFAS 115, but the accounting for a move to the trading classification under paragraph 15(b) of Statement 115 does not apply [1]. According to SFAS115, paragraph 15 , the transfer of a security between categories of investments shall be accounted for at fair value. At the date of the transfer, the security's unrealized holding gain or loss shall be accounted

*Corresponding author: Veliota Drakopoulou, Forbes School of Business, Ashford University, San Diego, CA 92123, USA, Tel: 8007980584; E-mail: Veliota.Drakopoulou@ashford.edu

Received April 13, 2015; Accepted April 27, 2015; Published May 10, 2015

Citation: Drakopoulou V (2015) The DOW 30's Compliance with the Provisions of SFAS 159 and 157 for Investments in Equity Securities. Int J Account Res 3: 118 doi: 10.4172/2472-114X.1000118

Copyright: ( 2015 Drakopoulou V. This is an open-access article distributed under the terms of the Creative Commons Attribution License, which permits unrestricted use, distribution, and reproduction in any medium, provided the original author and source are credited. 
for as follows: (a) "For a security transferred from the trading category, the unrealized holding gain or loss at the date of the transfer will have already been recognized in earnings and shall not be reversed", (b) "For a security transferred into the trading category, the portion of the unrealized holding gain or loss at the date of the transfer that has not been previously recognized in earnings shall be recognized in earnings immediately".

SFAS159 is effective for fiscal years beginning after November 15,2007 , with earlier application permitted as of the beginning of the previous fiscal year provided the company makes the choice in the first 120 days of that year and also elects to apply FASB Statement No. 157, Fair Value Measurements (SFAS 157). In September 2006, the FASB issued Statement of Financial Accounting Standards No. 157, "Fair Value Measurements" ("SFAS 157"). SFAS 157 determines fair value, demonstrates the structure for quantifying fair value compromising with the generally accepted accounting principles ("GAAP") and magnifies required disclosures about fair value measurements. Fair value is defined under SFAS No. 157 as the price that would be received to sell an asset or paid to transfer a liability in the principal or most advantageous market in an orderly transaction between market participants on the measurement date. This statement does not require any new fair value measurements; rather, it applies to other accounting pronouncements that require or permit fair value measurements.

In November 2007, the FASB gave a one-year deferral for the fulfillment of SFAS 157 for nonfinancial assets and liabilities. SFAS 157 sets up a three-tier fair value hierarchy, which prioritizes the inputs used in measuring fair value. These tiers embody: Level 1, described as detectable inputs such as quoted prices in active markets; Level 2 , defined as inputs other than quoted prices in active markets that are either directly or indirectly observable; and Level 3, defined as unobservable inputs in which little or no market data exists, therefore requiring an entity to develop its own assumptions. SFAS 157 confirms the requisites of other FASB Statements that the fair value of a position in a financial instrument (including a block) that trades in an active market should be measured as the product of the quoted price for the individual instrument times the quantity held (within Level 1 of the fair value hierarchy). The quoted price should not be adjusted due to the size of the position relative to trading volume" (Summary of Statement No. 157, "Fair Value Measurements".)

\section{Controversy surrounding the fair value option of AFS and HTM securities}

One of the controversies surrounding SFAS 159 is the loophole strategy, known as "FAS 159 Mulligan" derived before the early adoption deadline of FAS 159 ran out, promoted to companies by investment advisors. According to the "loophole strategy", if a company has less than honorable intentions, it could use SFAS 159 the way many investment advisors have suggested to identify all held-to-maturity (HTM) stocks that are underwater or available-for-sale (AFS) loans with higher interest rates than current market rates, and apply SFAS 159 to elect to measure underwater stocks and expensive loans at fair value. Then, record the loss in retained earnings bypassing the loss from the income statement. Lastly, drop the fair value treatment altogether by selling the underwater stocks or refinancing pricey loans and by purchasing replacement instruments valued at historical cost [3]. Although, SFAS 159 raised the bar for disclosure requirements and improved investors, analysts, and financial statement users understanding of managements' rationale for implementing the $\mathrm{FVO}$, at the same time, prospects entities to structure transactions that are intended to lever a specific accounting effect. Companies by appointing the fair value option for underwater investments in certain securities can move those securities from the AFS and HTM categories into the trading category and record the unrealized losses as an essential portion of the cumulative-effect adjustment to retained earnings without reproducing any losses on the securities in the income statement even if the securities subsequently are sold [4].

James L. Kroeker, Deputy Chief Accountant of the U.S. Securities and Exchange Commission (SEC) in his speech on the 2007 conference on "Principles-Based Accounting" interprets how the "transition provisions of SFAS 159" give entities the alternative to report certain financial assets and liabilities they contain upon adoption of the fair value measurement. Upon appointing fair value measurement any difference between fair value and carrying value of the asset or liability, involving any amounts inscribed in other comprehensive income, are entered promptly to retained earnings. Yet, formerly adoption of the fair value election for a given asset or liability is irrevocable. Consequently, some might advocate that an entity should elect the fair value option for certain existing investment assets where the carrying amount is less than fair value. This would grant the writing- down of the value of an asset lacking a charge to the income statement. While this might be granted for in the transition provisions, some might propose that entities would then have the capacity to trade the asset right after adopting the fair value option lacking to recognize a loss and then buy back an identical asset soon after the sale without appointing the asset like a fair value investment. Kroeker [2] confirmed that the SEC staff will persist on having an interest in activities that do not promote the objective of the accounting standard and provide perplexity to investors rather than significant information.

McGladrey and Pullen [5] discussed SFAS 115 as amended by SFAS 159 and the possible reasons for which companies are not rushing to take advantage of the "free pass" opportunity located in FAS 159's transition provisions to restructure their investment portfolios. The perceived free pass is based on the belief that entities can reclassify to the trading account held-to-maturity HTM and AFS underwater securities currently valued less than their "cost basis" and then sell those securities without reporting the loss in the income statement. The nest step of the "free pass" strategy would be to repurchase with a higher yield identical or similar securities to the ones sold. According to McGradrey [5], the reasons companies are not rushing to take advantage of this strategy are: (1) consideration of the principle objective of FAS 159, (2) the required early adoption of Financial Accounting Standards Board Statement No. 157, Fair Value Measurements, concurrent to the early adoption requirements of FAS 159, and (3) entities previous assertions about their intent and ability to hold underwater HTM and AFS securities to maturity or recovery. Entities are required to evaluate which HTM and AFS securities have a current fair value less than cost to determine whether such decline is considered "other than temporary" (OTT), under Financial Accounting Standards Board Statement No.115, Accounting for Certain Investments in Debt and Equity Securities, as amended and interpreted by FAS 159 . The "intent and ability" to hold these securities until their value is recovered, must be asserted by companies to avoid required OTT impairment charges. Therefore, if management disclosed on the entity's financial statements the "intent and ability" to hold underwater securities former to appropriating FAS 159 and subsequently adopts FAS 159 with the intent to trade these securities as determined in the "free pass" strategy, then the initial assertion would be questioned. FAS 159 should not be used to evade income statement charges or for objectives inconsistent with its stated objectives. Entities prior to employing the "free pass" strategy should 
contemplate necessary "OTT impairment charges" preceding the adoption provisions of FAS 159.

MCGeorge [6] deliberates the advantages of adopting the provisions of Financial Accounting Standards No. 157 and 159 for credit unions and publicly traded banks. It is determined that under FAS 157, investments are "marked-to-market" and the measurement used is the security's fair value while FAS 159 accords financial institutions the alternative to report the value of assets exercising the fair value. Credit unions are forced to declare low levels of capital, so they don't have to maximize accounting income to gratify shareholders or reflect an elevated return on equity. Credit unions with "high capital ratios" could stipend from adopting FAS 159 in the short-term since reclassifying investments would decrease the capital ratio and increase earnings. In the long run the reclassification would cause a brief distinction in credit union's capital structure since the capital would be intensified to the future.

McGeorge [6] stipulates that public traded banks by appropriating FAS 159 could ameliorate prospective earnings by trading their lowbearing investments and reinvesting at present yields without touching the income statement since financial analysts concentrate on future income and FAS 159 overstates a bank's stock. Banks captured the great advantages of the early adoption of the FAS 159 provisions by reclassifying their securities to the fair value and sprint losses straight to the shareholders' equity, then exchanged the securities without the loss in the income statement since the book value corresponded to the market value after the reclassification.

\section{Sample selection, sources, and analysis of data}

The quarterly financial statements (10-Qs) as of June 30, 2008 of the 30 companies comprising the Dow Jones Industrial Average were examined since it envelops a group of very large corporations with

\begin{tabular}{|c|c|c|c|}
\hline Company & SFAS No. 159 & SFAS No. 157 & Classification of \\
\hline & & & \begin{tabular}{|l|} 
Equity Securities \\
\end{tabular} \\
\hline $3 \mathrm{M} \mathrm{Co}$ & No & Yes & Level 1. \\
\hline Alcoa Inc & No & Yes & Level 1 \\
\hline American Express Co & Yes & Yes & Level 1 \\
\hline AIG, Inc & Yes & Yes & Level 1 \\
\hline AT\&T, Inc. & No & Yes & Level 1 \\
\hline Bank of America, Co. & Yes & Yes & Level 1 \\
\hline Boeing, Co. & No & Yes & Level 1 \\
\hline Caterpillar, Inc. & Yes & Yes. & Level 1 \\
\hline Chevron, Corp. & No & Yes & Level 1 \\
\hline Citigroup, Inc. & Yes & Yes & Level 1 \\
\hline E.I. du Pont & No & Yes & Level 1 \\
\hline Exxon Mobile Corp. & No & Yes & Level 1 \\
\hline GE Co. & No & Yes & Level 1 \\
\hline General Motors, Corp. & Yes & Yes & Level 1 \\
\hline Hewlett-Packard Co. & Yes & Yes & Level 1 \\
\hline Intel Corp. & Yes & Yes & Level 1 \\
\hline IBM & Yes & Yes & Level 1 \\
\hline Johnson \& Johnson & Yes & Yes & Level 1 \\
\hline JP Morgan \& Chase \& CO. & Yes & Yes & Level 1 \\
\hline McDolalds Corp. & No & Yes & N/A \\
\hline Merck \& Co., Inc. & Yes & Yes & Level 1 \\
\hline Microsoft Corp. & Yes & Yes & SFAS No. 115 \\
\hline Pfizer, Inc. & No & Yes & Level 1 \\
\hline Coca-Cola Co. & Yes & Yes & Level 1 \\
\hline Home Depot, Inc. & $\mathrm{N} / \mathrm{A}$ & $\mathrm{N} / \mathrm{A}$ & $\mathrm{N} / \mathrm{A}$ \\
\hline Procter \& Gamble, Co. & No & Yes & Level 1 \\
\hline United Technologies, Corp. & Yes & Yes & Level 1 \\
\hline Verizon & Yes & Yes & Level 1 \\
\hline Wal-Mart Stores, Inc. & Yes & Yes & $\mathrm{N} / \mathrm{A}$ \\
\hline Walt Disney & Yes & Yes & $\mathrm{N} / \mathrm{A}$ \\
\hline
\end{tabular}

Figure 1: Companies from the Dow 30 adopted both SFAS-159 and SFAS-157. adequate financials to dedicate to the accumulation of the essential information to correspond to the reporting requirements of SFAS No. 159. The 10-Qs were obtained from the Securities and Exchange Commission (SEC) Edgar filing system. I scanned through the notes of the individual financial statements of each company to find disclosed information regarding the provisions of SFAS No. 159 and SFAS No. 157 for investments in equity securities.

\section{Research Questions}

The research questions addressed in this study were designed to analyze the financial statements of the sample companies to determine whether, and how well, the qualitative and quantitative disclosure requirements of SFAS No. 159 were being followed in the first year of reporting under its provisions. Specifically, I sought to address the following questions:

(1) How many companies:

(a) Adopted SFAS No. 157 and SFAS No. 159?

(b) Complied with the provisions of SFAS No. 159 to determine the fair value using quoted market prices to classify their investments in equity securities?

(c) Complied with the qualitative requirements of SFAS No. 159?

(2) How many companies provided a detailed analysis of the cumulative-effect adjustment to the opening balance of retained earnings as of the date of initial adoption, including a comparison of the previous carrying amount and the new fair value-carrying amount for the affected assets and liabilities?

(3) How many companies provided information about where in the income statement changes in fair values of assets and liabilities reported at fair value are included in earnings?

\section{Results of research question 1}

Eighteen companies from the Dow 30 adopted both SFAS-159 and SFAS-157 while twelve companies adopted only SFAS-157, as shown in Figure 1. All companies who adopted SFAS-159 were found to comply with the qualitative requirements to disclose their objective for electing the fair value option for each eligible item or for a group of eligible items. However, there is a lack of consistency in the amount of information that was disclosed. Some companies disclosed information about fair value measurements more clearly and more extensively than others. The following disclosures from three of the companies in the sample illustrate this point:

Other assets include equity investments held by Principal Investing, available-for-sale (AFS) equity securities and certain retained residual interests in securitization vehicles, including interest-only strips are accounted for at fair value in accordance with SFAS 159 . Substantially all of other assets are eligible for, and the Corporation has not chosen to, elect fair value accounting at June 30, 2008 and December 31, 2007.

Note 8: Available-For-Sale Securities. Financial Products, primarily Cat Insurance, has investments in certain debt and equity securities that have been classified as available-for-sale in accordance with Statement of Financial Accounting Standards No. 115 (SFAS 115), "Accounting for Certain Investments in Debt and Equity Securities" and recorded at fair value based upon quoted market prices. These fair values are included in "Other assets" in the Consolidated Statement of Financial Position. Unrealized gains and losses arising from the revaluation of availablefor-sale securities are included, net of applicable deferred income taxes, 
Citation: Drakopoulou V (2015) The DOW 30's Compliance with the Provisions of SFAS 159 and 157 for Investments in Equity Securities. Int J Account Res 3: 118. doi: 10.4172/2472-114X.1000118

in equity ("Accumulated other comprehensive income (loss)" in the Consolidated Statement of Financial Position).

Many, but not all, of our financial instruments are carried at fair value. For example, substantially all of our cash equivalents, short-term investments and long-term investments are classified as available-forlosses, net of tax, reported in other comprehensive income.

\section{Results of research question 2}

To facilitate users' understanding of how the fair value option was elected at initial adoption with respect to existing financial assets and liabilities, the Board decided to require a detailed analysis of the cumulative-effect adjustment to the opening balance of retained earnings as of the date of initial adoption, including a comparison of the previous carrying amount and the new fair value carrying amount for the affected financial assets and financial liabilities. The cumulative-effect adjustment should include removing from the statement of financial position the difference between the carrying amount and fair value of eligible items for which the fair value option is elected at the effective date. To further facilitate users' understanding, the Board also decided to require disclosure of additional information about management's reasons for electing the fair value option, and, for instances in which an entity elects the fair value option for only certain instruments within a group of similar instruments, disclosure of management's reasons for only partial election (SFAS159-25, A49).

As shown in Figure 2, eleven companies disclosed the carrying value of financial instruments prior to adoption of SFAS No. 159 in the notes to their financial statements while the remaining nineteen companies did not make any of the required disclosures. Additionally, the cumulative-effect adjustment of financial instruments' fair value was disclosed by AIG, Inc. (\$1,003), Citigroup, Inc. (99), and JP earnings statement. Eight companies out of the $30 \mathrm{DOW}$ disclosed the cumulative-effect adjustment of the fair value of financial instruments to the footnotes to their financial statements, and nineteen companies did not make any disclosures about the fair value cumulative-effect adjustment of financial instruments. Lastly, eleven companies out of the $30 \mathrm{DOW}$ disclosed to the notes of their financial statements the fair value of financial instruments after adoption of SFAS No. 159, while the remaining nineteen companies did not make any reference about it.

\section{Research question 3}

For each period for which an income statement is presented, sale securities and are carried at fair value, with unrealized gains and Morgan and Chase and Co. 199 to the opening balance of their retained

entities shall disclose the following about financial instruments for which the fair value option has been elected: (a) For each line item in the statement of financial position, the amounts of gains and losses from value changes included in earnings during the period and in which line in the income statement those gains and losses are reported (SFAS159, 19 (a), page 9-10) Additionally, Table 1, represents a fair value hierarchy table set forth in Statement 157, supplemental to (c) provide information about where in the income statement changes in fair values of financial instruments reported at fair value are included in earnings and (d) voluntarily integrate selected disclosures (SFAS159$31, \mathrm{~B} 6)$.

From Figure 3, we can see that nineteen companies out of the total $30 \mathrm{DOW}$ disclosed in the footnotes to their financial statements the fair value measurements of marketable securities. Secondly, the quoted prices in active markets for identical financial assets (Level 1,2 and 3) were disclosed by nineteen companies out of the Dow 30 in the footnotes to their financial statements while Home Depot, Inc. stated that it doesn't own market securities. Thirdly, seventeen companies

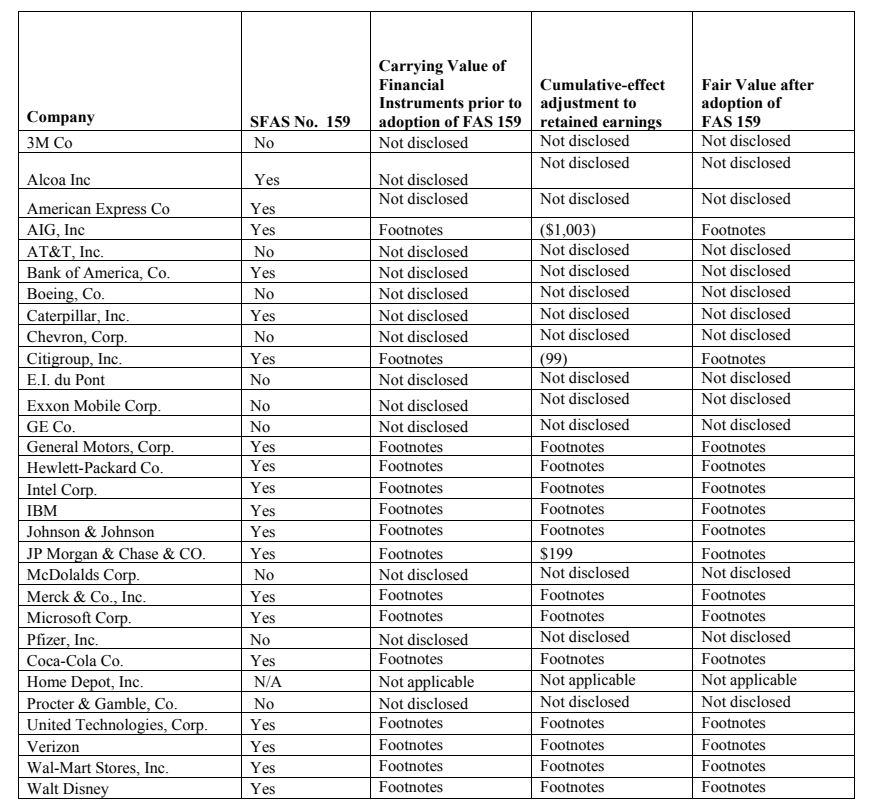

Figure 2: Companies disclosed the carrying value of financial instruments.

Changes in Fair Values for the 12-Months Period Ended December 31 2008, for Items Measured at Fair Value Pursuant to Election of the Fair Value Option

\begin{tabular}{|c|c|c|c|c|c|c|c|c|}
\hline & & & & & & & & \\
\hline Description & \begin{tabular}{|c|} 
Fair Value \\
Measurements \\
$12 / 31 / 08$
\end{tabular} & $\begin{array}{l}\text { Quoted Prices in } \\
\text { Active Markets } \\
\text { for Identical } \\
\text { Assets (Level 1) }\end{array}$ & \begin{tabular}{|c|} 
Significant \\
Other \\
Observable \\
Inputs (Level 2)
\end{tabular} & $\begin{array}{c}\text { Significant } \\
\text { Unobservable } \\
\text { Inputs (Level 3) }\end{array}$ & $\begin{array}{l}\text { Other gains } \\
\text { and Losses }\end{array}$ & $\begin{array}{c}\text { Interest } \\
\text { Income } \\
\text { and Loans }\end{array}$ & $\begin{array}{c}\text { Interest } \\
\text { Expense on } \\
\text { Long-Term Debt }\end{array}$ & $\begin{array}{c}\text { Total Changes in Fair Values } \\
\text { Included in Current-Period } \\
\text { Earning }\end{array}$ \\
\hline Trading Securities & $\$ 115$ & $\$ 105$ & $\$ 10$ & & & & & \\
\hline $\begin{array}{l}\text { Available for Sale } \\
\text { Securities }\end{array}$ & 75 & 75 & & & & & & \\
\hline Loans & 150 & 0 & 100 & $\$ 50$ & $\$(3)$ & $\$ 10$ & & $\$ 7$ \\
\hline Derivatives & 60 & 25 & 15 & 20 & & & & \\
\hline $\begin{array}{l}\text { Private equity } \\
\text { investments* }\end{array}$ & 75 & 0 & 25 & 50 & (18) & & & $(18)$ \\
\hline Long-Term Debt & (60) & (30) & (10) & (20) & 13 & & $\$(4)$ & 9 \\
\hline
\end{tabular}

*Represents investments that would otherwise be accounted for under the equity method of accounting

Table 1: Loans are included in loans and lease receivables in the statements of financial position. As of December 31,2008, approximately $\$ 160,000$ of lease receivables are included in loans and lease receivables in the statement of financial position and are not eligible for the fair value option. 
Citation: Drakopoulou V (2015) The DOW 30's Compliance with the Provisions of SFAS 159 and 157 for Investments in Equity Securities. Int J Account Res 3: 118. doi: 10.4172/2472-114X.1000118

Page 5 of 6

\begin{tabular}{|c|c|c|c|c|c|c|c|}
\hline Company & $\begin{array}{l}\text { SFAS } \\
\text { No. } 159\end{array}$ & $\begin{array}{l}\text { Fair Value } \\
\text { Measurements of } \\
\text { Marketable } \\
\text { Securities } \\
\end{array}$ & $\begin{array}{l}\text { Quoted Prices in } \\
\text { Active Markets for } \\
\text { Identical Financial } \\
\text { Assets (Level 1) }\end{array}$ & $\begin{array}{l}\text { Significant Other } \\
\text { Observable Inputs } \\
\text { (Level 2) }\end{array}$ & $\begin{array}{l}\text { Significant Other } \\
\text { Unobservable Inputs } \\
\text { (Level 3) }\end{array}$ & $\begin{array}{l}\text { Trading Gains and } \\
\text { Losses }\end{array}$ & $\begin{array}{l}\text { Total changes in Fair } \\
\text { Values Included in } \\
\text { Current-Period } \\
\text { Earnings }\end{array}$ \\
\hline $3 \mathrm{M} \mathrm{Co}$ & No & Footnotes & Footnotes & Footnotes & Footnotes & Disclosed & Disclosed \\
\hline Alcoa Inc & Yes & Footnotes & Footnotes & Footnotes & Footnotes & Disclosed & Disclosed \\
\hline American Express Co & Yes & Footnotes & Footnotes & Footnotes & Footnotes & Disclosed & Disclosed \\
\hline AIG, Inc & Yes & Footnotes & Footnotes & Footnotes & Footnotes & Disclosed & Disclosed \\
\hline AT\&T, Inc. & No & Not disclosed & Not disclosed & Not disclosed & Not disclosed & Not disclosed & Not disclosed \\
\hline Bank of America, Co. & Yes & Footnotes & Footnotes & Footnotes & Footnotes & $(\$ 389)$ & 3434 \\
\hline Boeing, Co. & No & Footnotes & Footnotes & Footnotes & Footnotes & Not disclosed & Not disclosed \\
\hline Caterpillar, Inc. & Yes & Footnotes & Footnotes & Footnotes & Footnotes & $\$ 36$ & $\$ 1$ \\
\hline Chevron, Corp. & No & Not disclosed & Not disclosed & Not disclosed & Not disclosed & Not disclosed & Not disclosed \\
\hline Citigroup, Inc. & Yes & & & & & & \\
\hline E.I. du Pont & No & Not disclosed & Not disclosed & Not disclosed & Not disclosed & Not disclosed & Not disclosed \\
\hline Exxon Mobile Corp. & No & Not disclosed & Not disclosed & Not disclosed & Not disclosed & Not disclosed & Not disclosed \\
\hline GE Co. & No & Not disclosed & Not disclosed & Not disclosed & Not disclosed & Not disclosed & Not disclosed \\
\hline General Motors & Yes & Footnotes & Footnotes & Footnotes & Footnotes & Footnotes & Footnotes \\
\hline Hewlett-Packard Co. & Yes & Footnotes & Footnotes & Footnotes & Footnotes & Footnotes & Footnotes \\
\hline Intel Corp. & Yes & Footnotes & Footnotes & Footnotes & Footnotes & Footnotes & Footnotes \\
\hline IBM & Yes & Footnotes & Footnotes & Footnotes & Footnotes & Footnotes & Footnotes \\
\hline Johnson \& Johnson & Yes & Footnotes & Footnotes & Footnotes & Footnotes & Footnotes & Footnotes \\
\hline JP Morgan \& Chase & Yes & Footnotes & Footnotes & Footnotes & Footnotes & Footnotes & Footnotes \\
\hline McDolalds Corp. & No & Not disclosed & Not disclosed & Not disclosed & Not disclosed & Not disclosed & Not disclosed \\
\hline Merck \& Co., Inc. & Yes & Footnotes & Footnotes & Footnotes & Footnotes & Footnotes & Footnotes \\
\hline Microsoft Corp. & Yes & Footnotes & Footnotes & Footnotes & Footnotes & Footnotes & Footnotes \\
\hline Pfizer, Inc. & No & Not disclosed & Not disclosed & Not disclosed & Not disclosed & Not disclosed & Not disclosed \\
\hline Coca-Cola Co. & Yes & Footnotes & Footnotes & Footnotes & Footnotes & Footnotes & Footnotes \\
\hline Home Depot, Inc. & $\mathrm{N} / \mathrm{A}$ & Not applicable & Not applicable & Not applicable & Not applicable & Not applicable & Not applicable \\
\hline Procter \& Gamble & No & Not disclosed & Not disclosed & Not disclosed & Not disclosed & Not disclosed & Not disclosed \\
\hline United Technologies & Yes & Footnotes & Footnotes & Footnotes & Footnotes & Footnotes & Footnotes \\
\hline Verizon & Yes & Footnotes & Footnotes & Footnotes & Footnotes & Footnotes & Footnotes \\
\hline Wal-Mart Stores, Inc. & Yes & Footnotes & Footnotes & Footnotes & Footnotes & Footnotes & Footnotes \\
\hline Walt Disney & Yes & Footnotes & Footnotes & Footnotes & Footnotes & Footnotes & Footnotes \\
\hline
\end{tabular}

Figure 3: Companies out of the total $30 \mathrm{DOW}$ disclosed in the footnotes to their financial statements

from the DOW 30 disclosed in their footnotes the trading gains and losses from their financial instruments while Bank of American, Co. (\$389 millions) and Caterpillar, Inc. (\$36 millions) disclosed the trading gains and losses specifically from marketable securities. Lastly, eleven companies from the DOW 30 did not disclose the total changes in fair value of their financial instruments in the current-period earnings while nineteen companies disclosed it.

\section{Discussion}

This study examines the disclosure of information for fair values for financial instruments and electing the option of trading classification for marketable securities applied by Dow 30 companies under the provisions of SFAS No. 157 and 159. The results indicated that the sample of companies complied with the qualitative guidelines outlined in the pronouncements. As a result, financial statement users were able to assess the companies three-tier fair value hierarchy, which prioritizes the inputs used in measuring fair value. Exchange-traded securities were classified within Level 1 of the fair-valuation hierarchy where quoted prices were available in an active market. However, some inconsistencies were found in meeting the quantitative requirements of SFAS No. 159. As a result, most of the financial statements reviewed were not providing enough information enabling financial statement users to evaluate how changes in fair values are affecting earnings for the period and understand the management's reasons for electing or partially electing the fair value option.
In respect to the adoption of SFAS No. 159, I do offer some quantitative disclosure requirements guidance with respect to investment portfolios. Entities considering adoption of SFAS No. 159 should carefully consider all of the requirements of both SFAS No. 159 and SFAS No. 157. The information stated below should be viewed as general advice and specific facts and circumstances need to be considered by each individual entity. Entities should select specific "held-to-maturity" (HTM) and "available-for-sale" (AFS) securities on an instrument-by-instrument basis and reclassify those securities to "trading securities" as of the date of adoption of SFAS No. 159. The election should be a one-time option for existing securities and the specific securities selected should be adjusted to their estimated fair value on the effective date of adoption, which was January 2, 2007 for early adoption or January 1, 2008 for calendar year entities. The adoption of the fair value option for selected HTM securities should not taint the remaining balance of the HTM securities and thus reclassification of the entire HTM portfolio to the trading portfolio is not required.

Additionally, all adjustments to fair value at the implementation date associated with the specific securities should not be charged through the income statement but charged as a cumulative-effect adjustment to beginning retained earnings. Any unrealized gains or losses on AFS instruments should be reclassified from accumulated other comprehensive income or loss to the cumulative-effect adjustment. Once the election is made should be irrevocable and 
Citation: Drakopoulou V (2015) The DOW 30's Compliance with the Provisions of SFAS 159 and 157 for Investments in Equity Securities. Int J Account Res 3: 118. doi: 10.4172/2472-114X.1000118

Page 6 of 6

all selected securities should be marked at their estimated fair value through results of operations for each subsequent reporting period. However, if the securities are sold, the recorded gains or losses should be realized at the date sold and no further adjustment would be required. Proceeds from sales could be invested in higher yielding investments and the entity would still have the option of classifying the newly purchased investments in accordance with SFAS No. 115 as HTM, AFS or trading securities.

Examining the quarterly reports (10-Q's) of the sample of companies for this study, I found that the disclosures of information about fair value option varied widely in terms of the amount of information disclosed and the format used in disclosing it. This lack of uniformity in disclosing information required by SFAS No. 159 could have made it unnecessarily difficult for financial statement users to assess the impact and potential impact of a company's use of fair value option on its results of operations and financial position. There are several possible explanations for the findings. These include: (1) a lack of a clear understanding of the provisions of SFAS No. 159; (2) a belief that some of the information was immaterial and as a consequence did not need to be disclosed; and (3) a desire to conceal potentially unfavorable information.

I am not in a position to assess the relative likelihood of each of these possibilities for the various companies that apparently failed to completely comply with the provisions of SFAS No. 159 and the reasons companies did not adopt SFAS No. 159. However, my general conclusion is that SFAS No. 159 provides little guidance on the documentation required to support an entity's election of the FVO. Statement 159 simply indicates that the decision to elect the FVO should be made at the date of election for each eligible item and it is upon an entity's judgment to establish an automatic election policy for certain eligible items. Statement 159 leaves room for discretion regarding documentation and in the absence of a well-developed preexisting policy for election, evidence of the election should be documented concurrently with the recognition or re-measurement of eligible items for companies to achieve proper quantitative disclosures.

\section{References}

1. FASB (2007) Statement of Financial Accounting Standards No. 159. The fair Value Option for Financial Assets and Financial Liabilities including an amendment of FASB Statement No. 155. FASB, Norwalk.

2. Kroeker LJ (2007) Speech by SEC Staff: Remarks before the 2007 Conference on Principles-Based Accounting and the Challenges of Implementation. U.S. Securities and Exchange Commission.

3. Leone M (2007) The FAS 159 Mulligan: A loophole in a new fair value accounting standard had investment advisors pushing clients to hide losses from investors. But most companies remained principled. CFO.com.

4. Ratcliffe AT (2007) The Finer Points of Fair Value. Journal of Accountancy

5. McGladrey Pullen (2007) FAS 159's Free Pass Myth.

6. McGeorge A (2007) Embrace the Luxury Of Basic Accounting. Credit Union Magazine 73: 1. 